\title{
A PARTICIPAÇÃO DA PUBLICIDADE NA SOCIALIZAÇÃo E NA FORMAÇÃo MORAL DA CRIANÇA
}

\author{
Adverstising's participation in children's socialization and moral formation
}

La participación de la publicidad en la socialización y en la formación moral de los niños

Lyvia Tascone $^{1}$

\section{Resumo}

Esse artigo contribui com o atual debate sobre o tema criança e publicidade, fundamentado em grupos de discussão realizados com crianças no Brasil e na França. A análise da complexa relação existente entre as crianças e a publicidade permitiu a descoberta de um pensamento crítico das crianças em relação à publicidade. No entanto, esse pensamento não restringe a participação da publicidade na socialização e formação moral das crianças, mas evidencia um intercâmbio ativo e complexo.

Palavras-chave: criança, publicidade, socialização, formação moral.

\begin{abstract}
This article contributes to the debate on children and advertising, based on focus groups with children, which took place in Brazil and in France. The analysis of the complex relationship between children and advertising enabled the discovery of children's critical thinking towards advertising. However, this critical thinking does not limit advertising's participation in children's socialization and moral formation, indicating a complex and active exchange.
\end{abstract}

Keywords: children, advertising, socialization, moral formation.

\section{Resumen}

${ }^{1}$ Professora Convidada no Centro Universitário das Faculdades Metropolitanas Unidas (FMU) no curso de PósGraduação em Comunicação e Marketing e Gerente de Pesquisa de Mercado na Unilever Brasil. Graduação em Comunicação Social com Habilitação em Publicidade e Propaganda pela Universidade de São Paulo (2008) e PósGraduação em Socio-Psicologia pela Fundação Escola de Sociologia e Política de São Paulo (2011). É mestre em Comunicação e Informação pela École Normale Supérieure de Lyon (2012). Dedica-se a estudar assuntos relativos à participação da publicidade na formação moral das crianças. E-mail: lyviatas@gmail.com 
A participação da publicidade na socialização e na formação moral da criança de Lyvia Tascone

Ese artigo contribuye con el debate actual sobre de los niños y de la publicidad, fundamentado en grupos de discusión hechos con niños en Brasil y en Francia. El análisis de la relación compleja existente entre los niños y la publicidad, ha posibilitado la descubierta en los niños de un pensamiento crítico en relación a la publicidad. Sin embargo, ese pensamiento no restringe la participación de la publicidad en la socialización y formación moral de los niños, evidenciando un intercambio activo y complejo.

Palabras-clave: niños, publicidad, socialización, formación moral.

\section{INTRODUÇÃO}

Estudos sobre crianças e publicidade ganham cada vez mais relevância. Alguns trabalhos tratam da influência e dos efeitos que a publicidade televisiva exerce sobre as crianças (MARTIN, 1997) e no seu comportamento como consumidoras. Com frequência a publicidade é tida como uma causa que provoca consequências negativas inevitáveis para as crianças, uma vez que elas são vistas como vulneráveis aos impactos da publicidade (LINN, 2004). Outros abordam temas específicos como o número de anúncios aos quais as crianças são expostas (O’BARR, 2008), a idade a partir da qual elas começam a diferenciar a publicidade do restante da programação televisiva (MARTIN, 1997), e se "entendem a natureza da publicidade" (MOSES e BALDWIN, 2005:186), ou seja, a intenção de vender.

Afim de contribuir com esse debate, o presente trabalho propõe uma discussão acerca da participação da publicidade na formação moral das crianças. Para isso valer-se-á de um arcabouço teórico fundamentado na intersecção da antropologia social com a antropologia da comunicação. Mais do que criticar ou defender a publicidade dirigida ao público infantil, o objetivo é entender a relação da criança com a publicidade, suas trocas e interações.

Segundo a antropologia social, “(...) ser humano é uma questão relacional, gerada na vivência social, (...), em formações sociais cujos participantes engajam uns com os outros como condição e pré-condição de suas existências (...)" (LAVE, 1996:149). Justamente por isso, as ações e reações humanas sempre devem ser analisadas levando-se em consideração o contexto no qual ocorrem. As experiências reais abrigam infinitas manifestações, dentre elas a publicidade, por meio das quais as crianças entram em contato com valores e normas sociais, que podem ou não participar do processo de socialização infantil. Isso porque "vivemos em uma sociedade na qual os agentes podem incorporar crenças, por meio de normas, modelos, valores, ideais, entre outros, sem possuírem os recursos materiais e as disposições para respeitar, perceber, alcançar ou conquistá-las” (LAHIRE, 2003:337). 
A participação da publicidade na socialização e na formação moral da criança de Lyvia Tascone

Assim, esse trabalho tem como principal objetivo o entendimento da participação publicitária na socialização e na formação moral da criança, para além da intencionalidade publicitária, ou seja, para além do estímulo ao consumo. Portanto, o papel da publicidade na vida das crianças será visto como "dinâmico e multifacetário" (BUCKINGHAM, 2003:18) e mais próximo da experiência real e extremamente complexa das crianças. $\mathrm{O}$ aprendizado moral e social ocorre através de atos morais contextualizados e não está restrito à experiência individual de cada criança. Dessa forma, as experiências sociais com outras crianças, com seus pais, no ambiente escolar e o convívio no espaço público, do qual a publicidade faz parte, contribuem com formação moral infantil.

Para que seja possível compreender o papel da publicidade na socialização e formação moral das crianças, é preciso considerar que um anúncio pode ser ineficaz em relação ao consumo, mas ainda assim participar da formação moral. Em outras palavras, a participação da publicidade na formação das crianças ultrapassa sua formação como consumidoras. Nesse sentido, a antropologia da comunicação contribui com uma reflexão pertinente segundo a qual em um ato comunicativo, as mensagens intencionalmente transmitidas por meio da linguagem, falada ou escrita, são complementadas ou até contraditas pelo silêncio, por imagens ou gestos (WINKIN, 1981). Dessa forma, os indivíduos são vistos como atores que participam ativamente do processo comunicativo, não importa se como produtores ou receptores de mensagens. Por isso, as crianças não deveriam ser tratadas como receptoras passivas de mensagens publicitárias, mas como seres ativos que irão interpretar e construir sentidos a partir do conteúdo recebido. A complexa relação entre crianças e publicidade é consequência de uma troca ampla, constante e multidirecional.

\section{MATERIAIS E MÉTODOS}

O desenvolvimento dessa pesquisa foi idealizado na forma de grupos de discussão feitos com crianças em idade escolar, sediados nas cidades de São Paulo (Brasil) e Lyon (França), entre agosto de 2011 e março de 2012. Optou-se por realizar os grupos de discussão nesses países visando uma análise comparativa dos resultados. A dinâmica escolhida possibilitou a análise dos discursos e o comportamento de oito grupos de crianças de sete a dez anos - quatro em cada país, buscando um entendimento mais profundo da complexa relação delas com a publicidade. Todos os grupos foram filmados para possibilitar uma análise posterior das discussões. 
A participação da publicidade na socialização e na formação moral da criança de Lyvia Tascone

Para garantir homogeneidade entre os participantes reuniram-se, no ambiente escolar, grupos com cinco ou seis crianças da mesma faixa etária para discutir temas pré-estabelecidos relacionados com a publicidade, ao longo de quarenta e cinco minutos. Uma escola particular frequentada por alunos de classe média alta foi escolhida para este estudo em cada um dos países $^{2}$. No Brasil e na França coube às instituições de ensino a seleção das crianças que participaram desta pesquisa. A realização dos grupos no ambiente escolar proporcionou um espaço com o qual as crianças estavam familiarizadas, facilitando assim a dinâmica da discussão.

Um único roteiro foi elaborado para se conduzir a discussão em ambos países, iniciando com temas que tratavam da rotina das crianças e sobre sua relação com os pais. Então introduzia-se o tema da televisão e da propaganda e na última parte de cada grupo foram exibidos cinco anúncios televisivos para fomentar a discussão sobre os filmes publicitários.

Os filmes usados em cada país eram distintos, mas optou-se por escolher aqueles de categorias, marcas e temas semelhantes. Assim, no Brasil e na França as crianças foram expostas a anúncios dos seguintes temas: duas propagandas de alimentos direcionadas ao público infantil em geral; brinquedo/artigo direcionado a meninas; brinquedo direcionado a meninos; e o comercial de um produto de tecnologia, teoricamente direcionado ao público adulto. As peças exibidas em cada país foram:

- Brasil: chocolate Batom, sandálias Barbie (Grendene), carrinhos de brinquedo Hot Wheels, chocolate em pó Toddy, e telefone celular Iphone.

- França: cereal matinal Chocapic (Nestlé), boneca Barbie, carrinhos de brinquedo Hot Wheels, Flunch (restaurante fast-food direcionado ao público infanto-juvenil) e telefone celular Iphone.

Ao longo das discussões foram utilizadas algumas técnicas de moderação para facilitar a discussão. Durante a discussão sobre a rotina, foi solicitado às crianças que fizessem um desenho ilustrativo. Já para introduzir o tema da televisão, elas foram orientadas a fazerem colagens que refletissem esse universo. Vale ressaltar que, ainda que os desenhos e as colagens tenham sido brevemente analisados, por opção da autora, o aprendizado exposto ao longo desse artigo considerou principalmente as discussões, reações e comportamentos das crianças dentro de cada grupo.

\footnotetext{
${ }^{2}$ Houve um acordo entre a autora e a direção de ambas as escolas de que os nomes das instituições e dos participantes não seriam divulgados.
} 


\section{RESULTADOS E ANÁLISES}

A reunião em grupos de discussão permitiu o fomento do debate sobre um tema de tal modo que viesse a espelhar a relação das crianças brasileiras e francesas com a publicidade. Vale citar desde já que os resultados desse trabalho de campo feito no Brasil e na França serão analisados conjuntamente, apenas indicando a qual país pertencem as citações utilizadas. Isso porque, ao contrário da hipótese inicial, houve mais similaridades do que diferenças entre os países. Ainda assim, qualquer particularidade ou diferença será indicada.

Ao serem informadas que o tema da discussão seria a publicidade, as primeiras reações das crianças foram idênticas em ambos os países: elas espontaneamente criticaram a publicidade.

"Me irrita, me irrita!” (Menino, 10 anos, França)

"É irritante!" (Menina, 8 anos, Brasil)

Através dessas declarações, percebe-se que as crianças compreendem e reproduzem o discurso predominantemente negativo que há no espaço público acerca da publicidade. A tentativa de demonizar a publicidade é reproduzida pelas crianças, de forma que o discurso delas acaba contribuindo para um pânico moral contra a publicidade (TASCONE, 2012). Apesar dessa primeira reação negativa, foi possível constatar que a publicidade ainda está muito presente na vida das crianças pois elas citam peças publicitárias específicas, reconhecem marcas e são capazes de cantar jingles de memória. Portanto, antes de analisar em profundidade a relação das crianças com a publicidade e como essa relação participa da sua socialização e formação moral, é também necessário desmembrar o discurso crítico delas.

A principal queixa das crianças acerca da publicidade refere-se à intencionalidade publicitária, ou seja, à sua razão de ser.

“É só uma propaganda pra fazer as crianças comprarem o produto." (Menino, oito anos, Brasil)

"É pra fazer a gente querer comprar." (Menino, sete anos, França)

Consequentemente, sempre que solicitado às crianças que explicassem ou justificassem qualquer aspecto de uma peça publicitária, a resposta mais ou menos padronizada era: "É para ajudar a vender o produto. " Convém destacar igualmente que as crianças são especialistas nos recursos e manobras usados pela criação publicitária. As crianças mencionam desde aspectos mais técnicos, como a manipulação de imagens por meio do programa Photoshop, montagem e edição, até estratégias de marketing como a venda casada e a interrupção de programas 
A participação da publicidade na socialização e na formação moral da criança

de Lyvia Tascone

televisivos no momento clímax para a exibição do intervalo comercial. Esse conhecimento é certamente um reflexo da presença intensa da publicidade no cotidiano infantil.

Por outro lado, a crítica das crianças não se restringia apenas à publicidade, mas também à aquisição do produto anunciado. Baseando-se nas próprias experiências ou na experiência de outras pessoas, as crianças sabem que o produto anunciado nem sempre corresponde àquele com o qual se deparam no momento da compra. Elas já se decepcionaram muitas vezes e, por isso, têm lembranças claras dessas surpresas desagradáveis.

"Eu cai nessa pegadinha. Eu comprei um desse do tubarão, não, do jacaré. Aí ele abria a boca assim, se ele passasse ele podia ou fechar a boca com você dentro, ou você passando ele fechava sem engolir você, mas aí nunca fechava, ele ficava lá." (Menino, 10 anos, Brasil)

Outro aspecto referente à crítica das crianças é o incômodo provocado pela dissonância entre o que é visto na publicidade e a vida real para além da experiência com o produto. As crianças, espontaneamente, criticam o fato da publicidade usar elementos imaginários e lúdicos para impulsionar vendas.

“Eles pegam as pessoas dos desenhos e fazem eles aparecerem nas propagandas.” (Menina, sete anos, França)

"E também porque um cachorro falante não existe, a gente sabe disso." (Menino, sete anos, França)

Para essas crianças, a presença na publicidade daquilo que não existe incomoda. Isso porque a publicidade se propõe a divulgar produtos reais. Dessa forma, a presença do lúdico é tida como enganadora e, portanto, não é bem aceita pelas crianças.

Outro aspecto importante que merece destaque é o fato do discurso crítico ser essencialmente negativo. Poucos aspectos positivos da publicidade foram mencionados. Algumas crianças brasileiras caracterizaram a publicidade como sendo engraçada e divertida, enquanto que na França elas disseram que a publicidade pode ser útil no momento de se escolher um presente. Como consequência de um discurso predominantemente negativo, nota-se uma crítica irrestrita e não-ponderada, de modo que até fatos verdadeiros presentes na publicidade, como o do exemplo abaixo, são considerados enganosos pelas crianças.

"Todas as propagandas não deviam ser enganosas, por exemplo as propagandas que falam 99\% proteção contra germes. Tipo claro que não é né? Tipo deve ser menos." (Menina, nove anos, Brasil)

Por outro lado, há diversos aspectos relacionados à publicidade que são ignorados por essa crítica infantil. Ainda que a intenção publicitária e o uso de recursos para impulsionar as 
A participação da publicidade na socialização e na formação moral da criança de Lyvia Tascone

vendas sejam criticados, tanto o consumo como o consumismo nunca são questionados. Emerge, portanto, um paradoxo pautado por uma crítica irrestrita, mas ao mesmo tempo excludente. Paradoxo esse cujo entendimento é essencial para que se possa compreender a relação real e prática das crianças com a publicidade: curiosamente, quando os produtos anunciados são apreciados pelas crianças, o próprio anúncio, o produto e seu consumo são automaticamente legitimados. Nesse sentido, após a exibição do anúncio do Iphone, algumas crianças francesas fizeram os seguintes comentários:

\footnotetext{
"Eu tenho um Iphone e é normal. Realmente funciona assim.” (Menino, 10 anos, França)

"É tudo verdadeiro." (Menino, 10 anos, França)

“Ipod não é um produto de má qualidade." (Menina, 10 anos, França)
}

Diante de um discurso infantil que critica a intencionalidade publicitária e ao mesmo tempo legitima o consumo é ainda mais pertinente entender a participação da publicidade na formação social e moral das crianças. Após a exibição de um anúncio direcionado para meninas, um garoto categoricamente declarou:

“Nunca vai me influenciar.” (Menino, 8 anos, Brasil)

A declaração do menino poderia estar correta se o efeito da publicidade estivesse limitado apenas ao consumo. Porém, independentemente do consumo, a publicidade possui valores e normas que podem contribuir com a formação moral e com a socialização das crianças. Uma vez expostas e colocadas em contato com esses valores e normas, as crianças podem experimentar emoções e sentimentos morais que culminariam em atos morais, possibilitando assim a participação da publicidade da formação moral. Por isso, uma análise que supera a intencionalidade publicitária de vender apresenta-se como indispensável.

Uma primeira evidência da participação da publicidade na formação moral diz respeito ao fato das crianças reconhecerem as normas e os valores presentes nos anúncios, estejam eles diretamente relacionados à história do anúncio (normas e valores evidentes) ou em segundo plano (normas e valores tácitos). Esse reconhecimento está sempre acompanhado de uma interpretação e de uma aproximação com a experiência pessoal de cada criança. As crianças possuem a tendência de criticar e desprezar normas e valores, tácitos ou evidentes, que contradigam seus valores e normas pessoais, bem como tendem a reforçar e reconhecer as normas e os valores previamente conhecidos e aceitos. Expostas a um mesmo anúncio, cada criança o interpretou de maneira distinta: 
A participação da publicidade na socialização e na formação moral da criança de Lyvia Tascone

"É uma menina interesseira." (Menina, 10 anos, Brasil)

"É pra conquistar uma pessoa por um alimento." (Menina, 10 anos, Brasil)

"Solidariedade, dividir com as pessoas, isso que mostra." (Menino, 10 anos, Brasil)

Vemos com base nesses comentários que há uma troca constante entre as normas e os valores presentes na publicidade e as normas e valores das próprias crianças. Justamente por isso, cada criança interpreta o anúncio de forma particular e única.

Por outro lado, a formação moral e a socialização das crianças estão em constante movimento e construção. As crianças reagem e agem quando são expostas a padrões morais em casa, no espaço público, na escola e também na publicidade. Esse contato com os valores e normas publicitários tem o potencial de desencadear uma reação complexa de formação moral nas crianças. Assim, pode-se afirmar que as críticas direcionadas pelas crianças à intencionalidade de vender não impossibilitam a contribuição da publicidade à sua formação moral.

O relacionamento ativo entre as crianças e a publicidade engloba também as emoções e os sentimentos morais que elas experimentam quando seus valores e normas previamente incorporados são confrontados com os valores e normas presentes nos anúncios publicitários. Isso porque, a formação moral é uma consequência do "contato constante com diversos valores e normas através do processo de socialização que provoca emoções e sentimentos morais e, portanto, atos morais." (TASCONE, 2012: 10). Dessa forma, ao provocar emoções e sentimentos morais, sejam eles positivos ou negativos, a publicidade está participando da formação moral das crianças. As emoções e os sentimentos morais que podem surgir do contato com a publicidade foram revelados por uma das crianças:

“...por exemplo, imagine uma menina. Ela quer comprar aquele negócio da Polly Pocket, mas como ela não enxerga os dedos, ela acha que é automático. É uma pena, porque isso vai estragar a diversão pra ela, e depois que ela comprar, ela vai ficar triste..." (Menino, 10 anos, França)

Os sentimentos de pena, ausência de diversão e tristeza são citados pois a situação imaginada da suposta decepção da menina com a compra do brinquedo mobiliza valores morais previamente incorporados e que são, portanto, capazes de provocar emoções concretas.

Ao participar do complexo sistema moral e dos sentimentos morais provocados pela negação ou reiteração de valores e normas, a publicidade pode provocar atos morais. Tal fato foi observado na situação descrita a seguir. Durante a exibição do anúncio do brinquedo Hot Wheels, um menino (a quem nos referiremos como "A") fez o seguinte comentário: 
“Eu odeio isso (...) É estúpido, é ridículo.” (Menino, 10 anos, França)

Esse comentário ilustra, primeiramente, que algo na publicidade provocou nele uma emoção negativa de raiva e desprezo. No entanto, o que transformou esse simples comentário em ato moral é o contexto no qual ele foi proferido.

Durante a exibição desse anúncio do Hot Wheels, outro garoto, "B", demostrava interesse. Interesse esse evidenciado pela atenção focada dedicada ao anúncio e também através do sorriso estampado em seu rosto. Essa emoção positiva de "B" foi vista e percebida por "A", que estava ao seu lado. Logo após essa constatação, "A" olhou diretamente para "B" e enfaticamente fez o comentário descrito acima. Com isso, tornou-se evidente sua intenção de impor uma lição moral, já que provocada por emoções e sentimentos morais, a "B".

Assim, o que transformou o comentário de "A" em ato moral não foi o conteúdo, mas o contexto e os gestos que o acompanharam aliados à causa que o motivou: substituir a emoção positiva provocada em "B" pelo anúncio, por uma emoção de desprezo sentida por "A" durante o mesmo anúncio. Com base nas suas emoções e sentimentos em relação à publicidade, ele agia como um empreendedor moral que visa convencer os demais a aceitar, incorporar e reproduzir valores e normas (BECKER, 1963). Nesse caso fica claro que o garoto não buscava um efeito no âmbito da sociedade, mas apenas no seu círculo imediato.

Ademais, atos morais podem ser relacionados para além das normas e dos valores de um único anúncio. Em ambos países, durante a exibição dos anúncios direcionados para meninas, a maioria dos meninos manifestou uma série de reações assim que o anúncio começava a ser exibido: viravam a cara, riam, se entreolhavam para verem as reações uns dos outros, se queixavam por serem "obrigados" a continuar assistindo, entre outros. Importante reforçar que essas reações ocorriam já nos primeiros instantes do anúncio, de modo que não podem ser confundidas com uma simples reação à execução criativa do anúncio, ou seja, serem explicadas por um "não gostar" do anúncio. Além disso, nenhum outro anúncio, mais ou menos apreciado, provocou nos meninos uma reação semelhante. A declaração abaixo, entre a primeira e a segunda exibição de um anúncio da Barbie, ilustra essas reações:

“Não, por favor não obrigue a gente a assistir isso de novo!” (Menino, oito anos, França)

Com esse comentário o garoto não estava apenas negando o anúncio em si, mas expôs o seu ponto de vista acerca de todas as coisas "de menina," que não deveriam ser apreciadas pelos meninos. Dessa forma, esse anúncio apenas reforçou o estereótipo de gênero (GOFFMANN, 1987) que o menino já havia previamente incorporado. 
A participação da publicidade na socialização e na formação moral da criança de Lyvia Tascone

Além de participar de atos morais e, portanto, da formação moral, a publicidade possui um papel importante na socialização das crianças. Nos grupos de discussão foi possível entender a relação das crianças com a sua capacidade crítica dirigida à publicidade. Para essas crianças saber que a publicidade não é apenas uma forma de entretenimento e que ela tem um claro objetivo de venda as diferencia das crianças mais novas que ainda não possuem esse conhecimento.

"Principalmente os pequenos, os pequenos se interessam pela publicidade e eles querem as coisas que veem na publicidade." (Menina, nove anos, França)

"Estimulava, estimulava. Até que eu avalio bem as propagandas e digo: isso é possível?" (Menina, oito anos, Brasil)

$\mathrm{O}$ aspecto mais interessante desse comportamento é que para essas crianças mais velhas saber para que serve a publicidade não é um meio usado para menosprezar as crianças mais novas, mas para se aproximar do mundo adulto. Compreender a intencionalidade publicitária é "um rito de passagem moderno, um aprendizado a partir de experiências vividas, um despertar e um pertencimento ao mundo de quem já cresceu. " (TASCONE, 2012: 96). Identificar o objetivo da publicidade contribui para a autoimagem e a autoestima das crianças e as brinda com um novo lugar na sociedade.

Um último aspecto relevante diz respeito ao fato de que os próprios grupos de discussão, que possibilitaram um contato com os anúncios seguido das discussões, também devem ser vistos como um momento de socialização. Durante os grupos, as crianças ampliaram seu conhecimento sobre um pensamento crítico a respeito da publicidade. Nessas discussões elas introduziram argumentos para desprezar ou exaltar a publicidade, argumentos esses que até então eram inéditos para algumas das crianças presentes. Ao longo de um dos grupos, um garoto praticamente não se manifestou. Ele apenas observava as reações dos demais e prestava atenção aos seus comentários. No entanto, nos minutos finais do grupo ele declarou:

"Mostra pra gente o que o produto pode fazer. Mas tem coisas que o produto não faz de verdade." (Menino, 10 anos, França)

As evidências coletadas ao longo dos grupos de discussão com as crianças nos dois países sugerem que a publicidade não apenas participa da formação das crianças como consumidoras mas pode exercer um papel amplo e complexo no processo de socialização e formação moral.

\section{REFLEXÕES}


A partir do trabalho de campo realizado foram observados diversos exemplos de como a publicidade participa do cotidiano das crianças. O discurso e o comportamento infantis estão repletos de normas, valores, emoções e atos morais desencadeados pelo contato com a publicidade, antes e durante os grupos. Mesmo que as crianças deslegitimem a publicidade por sua intenção (de vender), ela se legitima uma vez que fica evidente o complexo papel que exerce na prática. As declarações e atitudes das crianças denunciaram aspectos importantes da intensa relação entre as crianças e a publicidade, que pode, portanto, exercer um papel de participação da socialização e formação moral.

Vale ressaltar que em nenhum momento foi usado o termo "influência" para tratar da relação entre criança e publicidade. Isso porque, ao utilizar esse termo estar-se-ia considerando uma relação inevitável de causa e consequência pré-estabelecidas, na qual a criança exerceria um papel meramente passivo. Verificou-se, no entanto, que a publicidade está repleta de normas e valores que podem despertar emoções e sentimentos morais, levando a atos morais e, finalmente, a uma participação na formação moral. No entanto, essa participação depende da vivência social de cada criança e do contexto de socialização no qual está inserida.

Com esses resultados, aproxima-se de um entendimento do que realmente ocorre entre as crianças e a publicidade que revela trocas complexas, práticas e cotidianas. No entanto, os estudos não se esgotaram e ainda há diversos aspectos a serem investigados. Algumas questões que esse trabalho não chegou a abordar estão expostas a seguir:

1. Os mesmos resultados seriam reproduzidos em classes sociais mais baixas?

2. Os resultados no Brasil e na França foram muito similares. Haveria mais particularidades se o estudo fosse aplicado em outros países capitalistas?

3. E a Internet? Sua presença muda a relação das crianças com a publicidade? $\mathrm{Ou}$ ainda, a presença da Internet já contribui de alguma forma com os temas discutidos?

\section{CONSIDERAÇÕES FINAIS}

A relação cotidiana das crianças com a publicidade é essencialmente ativa e complexa. Através da pesquisa realizada, viu-se que os valores e as normas presentes na publicidade desencadeiam emoções, sentimentos morais e, portanto, podem participar da formação moral e da socialização das crianças por meio dos atos morais. Assim, pode-se concluir que o discurso crítico amplamente pronunciado pelas próprias crianças não impede a participação da publicidade à formação moral e social. 
A participação da publicidade na socialização e na formação moral da criança de Lyvia Tascone

A teoria de educação para as mídias, ou media literacy, considera que é essencial "criticar de forma positiva e/ou negativa os discursos da mídia encontrados na vida cotidiana" (EMERY e MCCABE, 2003:1). Portanto, os resultados apresentados ao longo desse artigo procuram referendar e contribuir com essa teoria, uma vez que ampliam o entendimento da relação criança-publicidade, evidenciando um intercâmbio ativo e complexo. O ensino de um pensamento crítico às crianças não deveria ignorar ou contradizer o pensamento crítico das próprias crianças. Isso porque ele geralmente está embasado em complexas experiências cotidianas. A educação para as mídias deveria complementar a troca que efetivamente já ocorre e que inclui a formação moral e a socialização.

\section{REFERÊNCIAS BIBLIOGRÁFICAS}

BECKER, H. S. Outsiders: Studies in the Sociology of Deviance. New York, The Free Press, 1963.

BUCKINGHAM, D. Media Education: literacy, learning and contemporary culture, Cambridge, Polity Press, 2003.

EMERY, W., MCCABE R. "The Development of Media Literacy among Grade Five Teachers Students - A Case Study”, In Canadian Journal of Learning and Technology, $\mathrm{n}^{\circ} 1$ Volume 29, Alberta, 2003: 1-15.

GOFFMAN, E. Gender Advertisements, New York : Harper \& Row Torchbooks, 1987

LAHIRE, B. "From the habitus to an individual heritage of dispositions. Towards a sociology at the level of the individual" In Poetics, Journal of Empirical Research on Culture, the Media and the Arts, Elsevier Science, Volume 31, September 2003: 329-355.

LAVE, J. "Teaching, as learning, in practice," In Mind, Culture and Activity, Volume 3, Number 3, 1996: 149-164.

LINN, S. Consuming kids: the hostile takeover of childhood. New York, The New Press: 2004: 288.

MARTIN, M.C. "Children's understating of the intent of advertising : A meta-analysis" In Journal of public policy \& marketing, Volume 16, Issue 2, Fall 1997: 205-216.

MOSES, L.J., BALDWIN, D.A. "What Can the Study of Cognitive Development Reveal About Children's Ability to Appreciate and Cope with Advertising?" In Journal of public policy \& marketing, Volume 24, Issue 2, Fall 2005: 186-201.

O'BARR, W. "Children and Advertising”, In Advertising \& Society Review, Volume 9, Issue 4, 2008: 26. 
A participação da publicidade na socialização e na formação moral da criança de Lyvia Tascone

TASCONE, L. La publicité et les enfants: socialisation et formation morale. Lyon: École Normale Supérieure de Lyon, 2012. Dissertação de Mestrado: 145.

WINKIN, Y. La nouvelle communication, Paris: Éditions du Seuil, 1981.

Artigo submetido: 28/09/2015

Artigo aprovado: 15/11/2015 